\title{
Biomimicry: (Innovation Inspired by Nature)
}

\section{Shivi Pathak}

Abstract-In today's modern times, where unsustainability threatens the very existence of mankind, revival of the philosophy of BIOMIMICRY opens up an avenue of probable solutions. It is an emerging horizon that looks to the natural world for ideas and inspiration for all kinds of design opportunities. In the search of sustainable building design and technology Biomimicry is an alternative solution. The inspiration from nature is driving force in architecture, resulting in majestic works of architecture. Biomimicry is about solution refined and developed by nature. These principles help designers to create products, processes, and policies that are well adapted to life on earth in its long run. Sometimes human designed solutions are cruder and more additive than the nature's solutions of the same problem. As we seek new ways to design and live sustainably, and in many cases have solved the same problems with a far greater economy of means. It is a design principle seeking sustainable solutions to divert attention towards nature's solution for human problems by consulting and emulating nature's tested and tried patterns and strategies. The primary idea is that necessity requires nature to be imaginative. Through this imagination, nature has successfully solved many of the problems that designers today are still struggling to solve. The behavioral and operational systems of the nature have a lot to teach and inspire us, provided we as architects and designers open our eyes towards it. The core idea is that nature already has all the remedies hidden in its deepest sanctuaries, we just have to be insolent and find it. Nature's consummate engineers - flora and fauna, have held in themselves the secret of survival. Aim is revealing how radical increase in resource efficiency can be achieved by looking to the nature for inspiration. For any sustainable building design, structural efficiency, water efficiency, zero-waste systems, thermal environment, and energy efficiency, Biomimicry is all about deriving solutions from nature.

Index Terms-BIOMIMICRY, Approach to Sustainability, Design solutions, Conceptual approach, as a Metaphor in Architecture, Design process in Architecture, Nature's Design Principles, Combination of Nature, Biology \& Architecture, Abstractions of good design from nature.

\section{INTRODUCTION}

"Biomimicry" (from bios, meaning life, and mimesis, meaning to imitate) literally means, "to imitate life". Biomimicry is the study of emulating and mimicking nature, to solve human problems. Biomimicry is a new discipline that studies nature's best ideas and then imitates these designs and processes to solve problems. The way the design process is approached is that designers look at nature,

Shivi Pathak has recently completed Bachelor's degree program in Architecture from Hitkarini College of Architecture and Town Planning, Jabalpur (M.P.) affiliated to R.G.P.V. University, INDIA specifically organisms or ecosystems, to solve a particular human need; and by doing so, converting these types of behavioral processes into man-made design solutions.

Imagine it as the combination of biology, nature and architecture into one composition.

Biomimicry argues that nature is the best, most influencing and the guaranteed source of innovation for the designers as a result of nature's 3.85 billion years of evolution, as it holds a gigantic experience of solving problems of the environment and its inhabitants. Architects have been searching for answers from nature to their complex questions about different kinds of structures, and they have mimicked a lot of forms from nature to create better and more efficient structures for different architectural purposes.

Architects had changed the way of design in a very prominent way as it was obvious in their writings, for instance the bold ideas of Le Corbusier and Frank Lloyd Wright. Le Corbusier thought that biology is the greatest word in architecture and planning. But the way they saw nature was still missing where the biological analogy was about superficially artistic picture from nature's wonders and creatures and that was clear in the buildings and products of the industrial age.

They had a superficial way for imitating and mimicking the forms of plants and animals. But from decades ago architects found other way of understanding nature as methods and analogies of growth and evolution.

Nature has learned how to achieve most efficient multifunctional structures, where designers and architects are trying to learn from nature and to get an optimized solution from it. Most of the current work focuses on the mimicry of structural forms from nature and using the digital tools as a source of defining and applying simulations on these complex structures.

Nature imitation has become the best approach for architecture and design to be a part of their built environment and to deliver a bold idea to their surroundings too.

Michael Pawlyn once rightly said: "You could look at nature as being like a catalogue of products, and all of those have benefited from a 3.8-billion-year research and development period. And given that level of investment, it makes sense to use it." Biomimicry is looking to nature to find a successful solution from different kinds of organisms that solved their problems from million years ago, as we can then put these design features into use in real-world architecture and structure. 


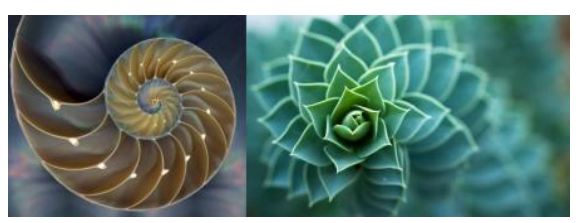

By

keeping

design

flaws to

a minimum, choosing the most appropriate material for design, providing recycling and solutions according to the circumstances, nature is an immense factory which is durable and aesthetic. Today designers, manufacturers and industries are seeking to

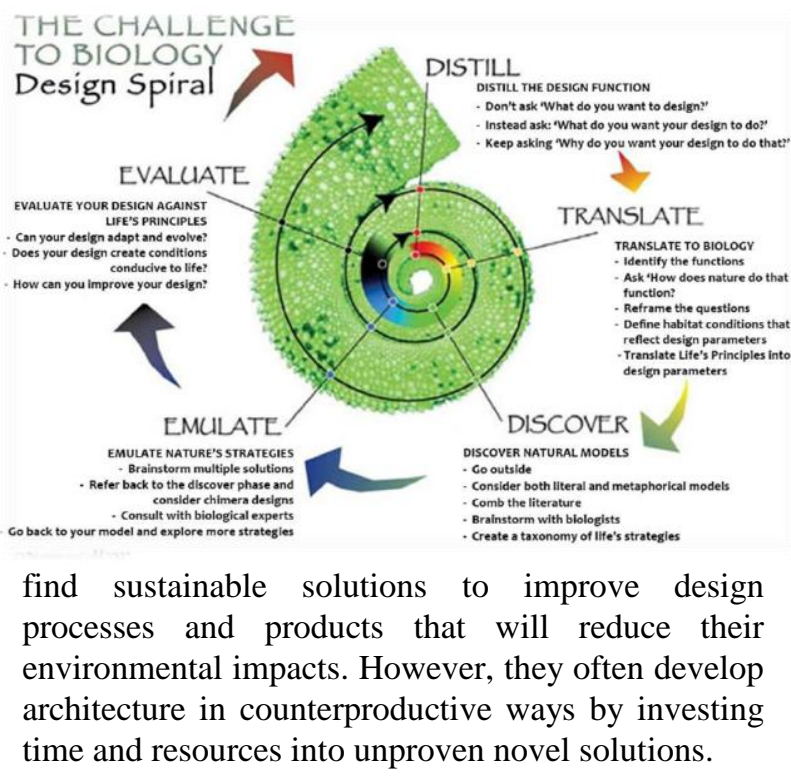

\section{BIOMIMICRY THEORETICAL FRAMEWORK}

\section{A. Principles of Biomimicry}

The biomimicry principles focus exclusively on nature's attributes; thereby implying that humans have much to learn from the billions of years of the natural world's evolutionary experience.

a- Nature uses only the energy it needs

b- Nature fits form to function

c- Nature recycles everything

d- Nature banks on diversity

e- Nature demands local expertise.
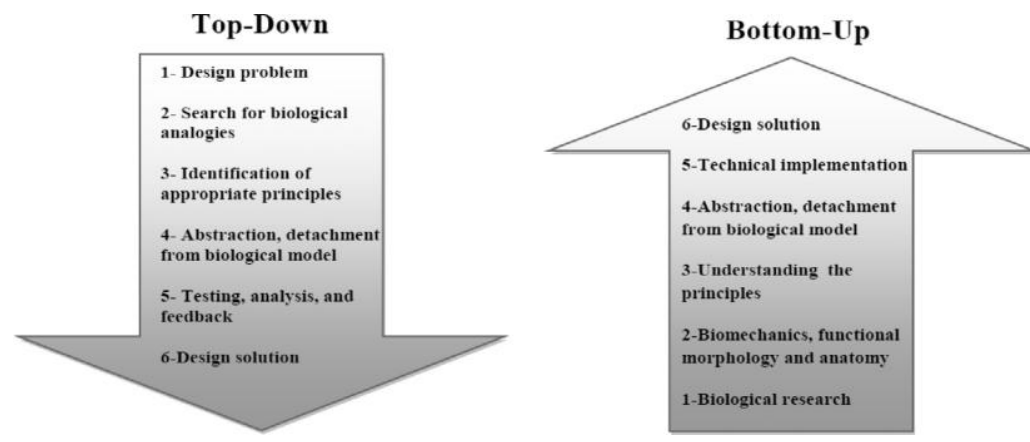

\section{B. Biomimicry Approaches}

Approaches to biomimicry as a design process typically fall into two categories:
- Defining a human need or designing problem and looking to the ways other organisms or ecosystems solve this, termed here Design looking to biology (Top-Down approach).

- Identifying a particular characteristic, behaviour or function in an organism or ecosystem and translating that into human designs, referred to as Biology influencing design (Bottom-Up approach).

- They also point to the way designers look to nature and organisms for solutions, where designers must recognize exactly their design problems and to match their problems with organisms and creatures that have solved similar problems.

\section{"The natural world and ecological system are maybe the best picture for what a sustainable world looks and performs like."}

"And if our built environment can function like these ecosystems, maybe that's the pinnacle of what sustainable design can be."

\section{Levels of Biomimicry}

There are three levels of biomimicry have to be applied also to design problems. From the biomimetic technologies and techniques, it is obvious and well noticed that there are three levels of mimicry: the organism level, behaviour level and ecosystem level.

- The organism level illustrates the mimicking of certain organism or the mimicry of a part from the whole organism, buildings on the organism level mimic a specific organism.

- The second level is the mimicry of behavior of which every organism behaves, buildings mimic how an organism behaves or relates to its larger context.

- The third level is the mimicking of the whole ecosystem and this level is considered the hardest level as it focuses on a functionally very hard issue to mimic, a building mimics the natural process and cycle of the greater environment.

Through each level there are five dimension which determine at which extent the mimicry exists. The design is listed as biomimicry in the way it looks like (form), what it is made of (material), how it is made (construction), how it works (process) and what its capability (function). These levels are very important and they complete the biomimicry approaches. 
Levels of biomimicry

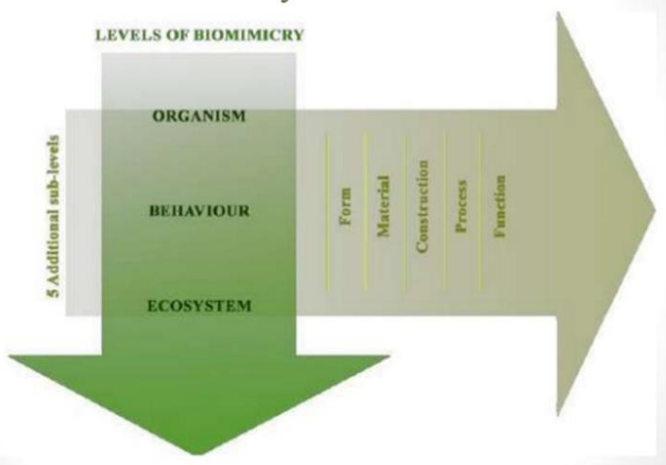

III. EXAMPLES

The East Gate designed by architect mick Pearce in conjunction with engineers at Arup associates is a large office and shopping complex in Harare, Zimbabwe. to minimize potential costs of regulating the building's inner temperature Pearce looked to the self-cooling mounds of African termites.
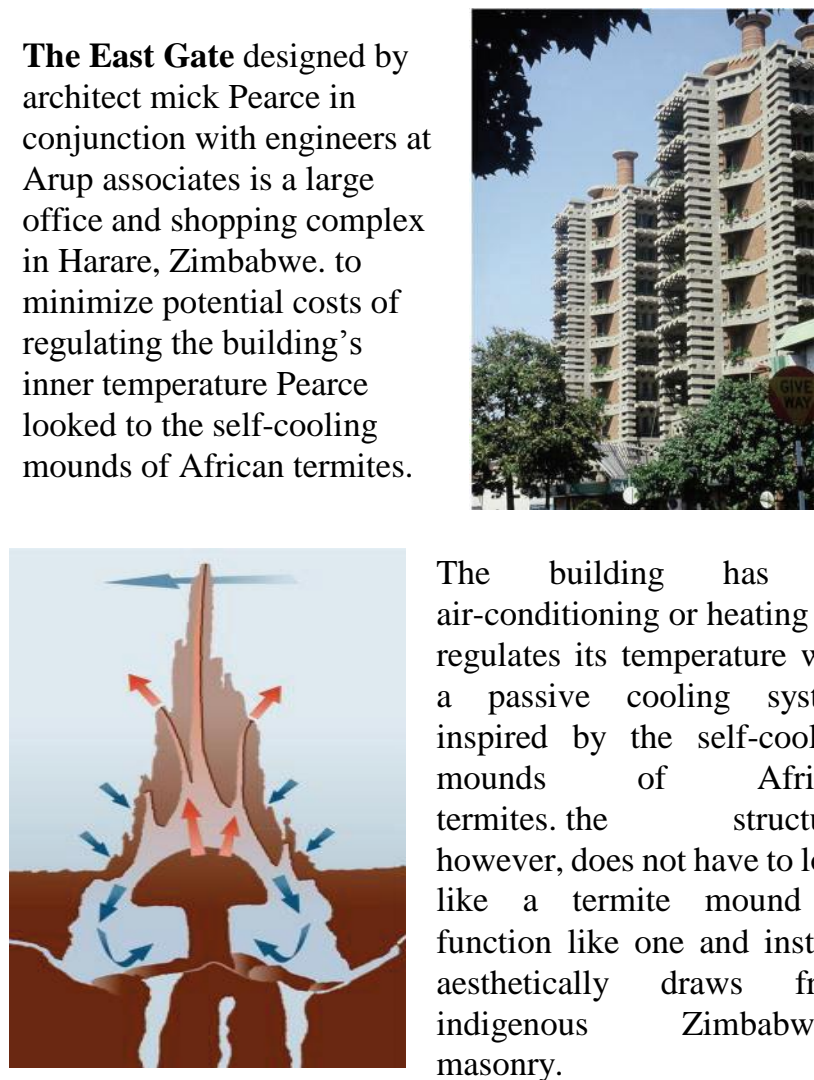

The building has no air-conditioning or heating but regulates its temperature with a passive cooling system inspired by the self-cooling mounds of African termites. the structure, however, does not have to look like a termite mound to function like one and instead aesthetically draws from indigenous Zimbabwean masonry.
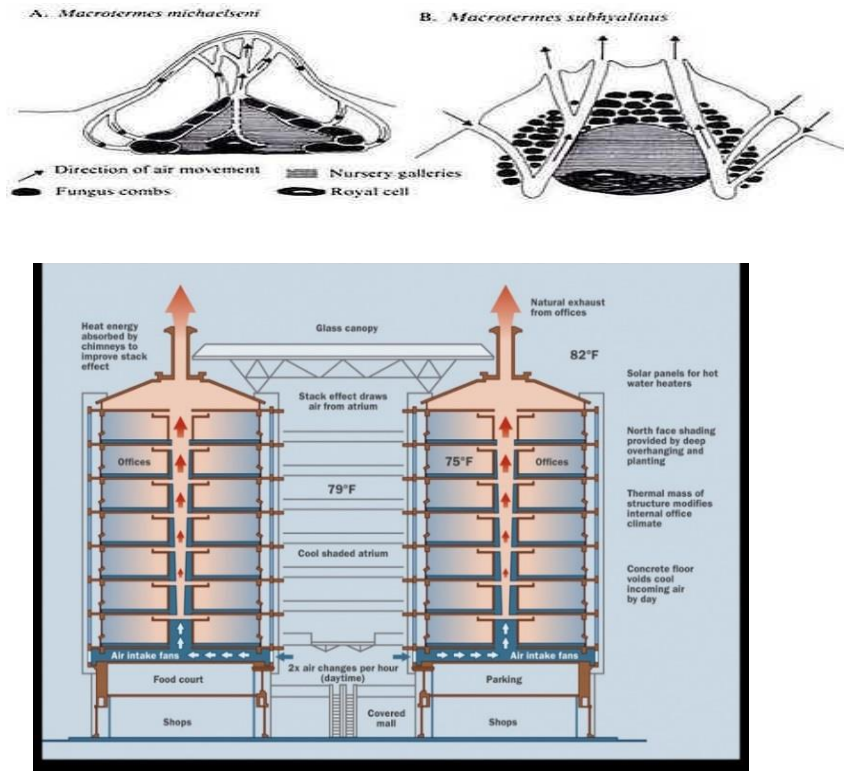

\section{HOW BIOMIMICRY CAN CHANGE OUR LIVES?}

The biomimicry term appeared in 1982 and it was invented and published by the famous scientist Janine Benyus in her most significant 1997 book (Biomimicry Innovation Inspired by Nature). Biomimicry was manifested in her book as "the new science that studies nature's models and imitating these designs to solve human problems". She also claimed looking to nature as a "Model, Measure, and Mentor" and she also suggested that the main aim of biomimicry is sustainability.

If we want to consciously emulate nature's genius, we need to look at nature differently. In biomimicry, we look at nature as model, measure, and mentor.

Nature as model: Biomimicry is a new science that studies nature's models and then emulates these forms, process, systems, and strategies to solve human problems - sustainably. The Biomimicry Guild and its collaborators have developed a practical design tool, called the Biomimicry

Nature as measure: Biomimicry uses an ecological standard to judge the sustainability of our innovations. After 3.8 billion years of evolution, nature has learned what works and what lasts. Nature as measure is captured in Life's Principles and is embedded in the evalute step of the Biomimicry-Desig-Spiral.

Nature as mentor: Biomimicry is a new way of viewing and valuing nature. It introduces an era based not on what we can extract from the natural world, but what we can learn from it.

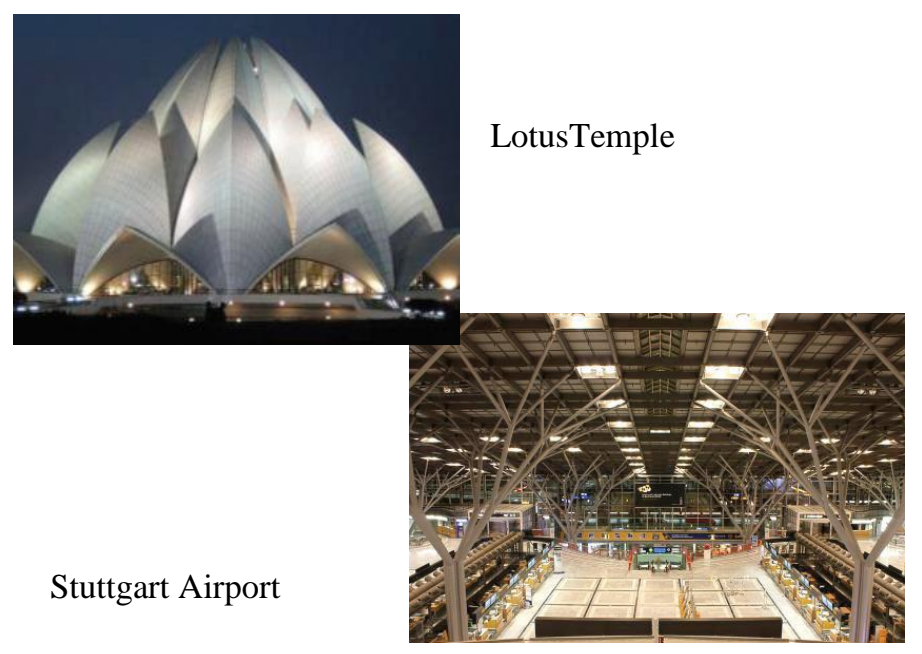

\section{BIOMIMICRY AND ARCHITECTURE}

Nature's designs are organic. Their shapes depend upon their functions. They are not linear. They are not based on lines and are therefore not limited by them. In nature, designs are organic; they are very small (only as big they need to be to fit the function). Human designs are very geometric and they are often larger than most natural inventions. Human's inventions are very brittle, stiff, and most of them depend on wheels for mobility. 


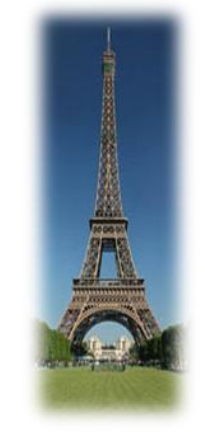

Architects have long taken inspiration from nature. In ancient Egypt columns were modeled on palm trees and lotus plants, and building designers have borrowed the shapes and proportions of natural forms ever since as they strived to achieve aesthetic perfection.

Some architects now believe that such biomimicry has more to offer than

They are copying found in nature to generate energy and water. And they using biomimetic gimmick, but makes

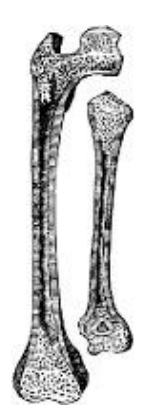
simply making buildings look good. functional systems provide cooling, even to desalinate insist that doing these designs is not just a financial sense.

\section{CONCLUSION}

a- Biomimetic architecture as the new contemporary architectural style of the $21 \mathrm{st}$ century that will revolutionize the architecture world in every way either the way architects think or how they inspire their ideas, the used materials in building, finishing materials to the world and building users. However, architecture has a small role to play in our daily life but it has a great influence in the world we live in.

b- This adaptation of technology has peaked in the second half of the 20th century with the discovery of new conventions of different materials has led to an emerging new styles and patterns of thinking that has revolted the traditional way of thinking in architecture.

c- Design biomimetics is a bridge that can connect architectural and design professions on a route to linking designed and environmental.

d- Design biomimetics can emphasize ways of thinking and designing that bring architecture and industrial design into a process of environmental and biological focus on more responsive, safer buildings.

e- Biomimetic technology would help us also overcome environmental issues, such as the greenhouse effect, global warming, or even the Ozone hole. By reducing the vast amount of $\mathrm{CO} 2$ emissions from the built material, and purifying the surrounding environments. One has to predict that this impressive new technology will be necessary to use in this 21 st century and we have to understand it well in order to be used in the right direction and contribute to the humanity development.

\author{
'The Current and \\ Coming Environmental \\ Challenges Are Most \\ Effectively Met If \\ Architects Look to And \\ Learn from The Natural \\ World'
}

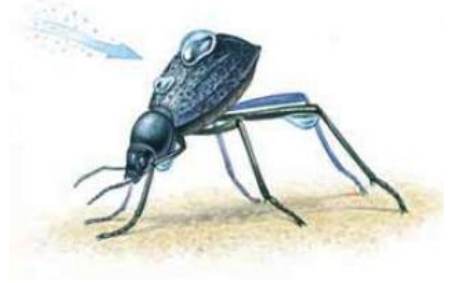

\section{Namibian Beetle and Water Collection,}

Impressed with the practicality of the beetle's innovative shell design and how it survives in such harsh conditions. So, tried to mimic the same type of technology into a building design to turn water droplets collected from fog into usable water. This level of Biomimicry, the organism level, took the technology that was found in the organism itself and mimicked it to produce an innovative, simple, man-made. sustainable solution to what was before seen as a difficult and complex problem.

Of the resulting projects, the highest profile one is the Sahara Forest Project, which seeks to help turn the tide of desertification. The Sahara Forest Project provides a way of beginning to turn this around, with a starring role for the humble fog basking beetle as its design starting point in the guise of seawater-cooled greenhouses. Together with another, in Pawlyn's words, 'proven' technology concentrated solar power - the project's systems approach could provide not only energy for entire cities in North

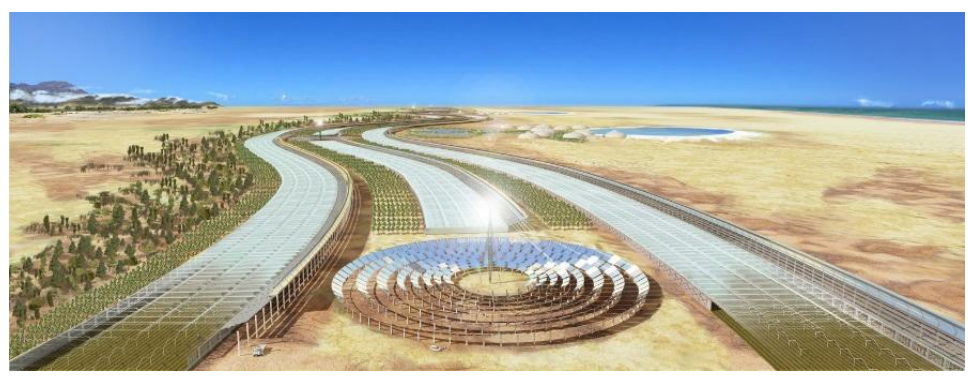

Africa and Middle East but also restore vegetation and agriculture to the desert.

Pawlyn acknowledges that biomimicry hasn't taken root in architecture, compared to industrial design and other aspects of engineering. 'We need to think through what it means to be truly sustainable, rather than just mitigating the negative impacts, and work out what that implies for our buildings and the systems into which they fit,' states Pawlyn, apparently confident biomimicry's day is coming. This requires the architectural world rethinking how such systems work and knowing what are the important areas that require focusing on. 'There are three key challenges: radical increases in resource efficiency, a move from a linear to a closed loop approach to materials, and moving from a fossil-fuel economy to a solar economy,' he writes.

\section{"We as a society are suffering from a Nature Deficit Disorder"}

-Shirish Beri 

"Look deep into Nature and then you will understand
everything better"

-Albert Einstein

Biomimicry in Architecture is a primer to an all-encompassing way of approaching building culture. It steps outside much of the conventions of architectural thinking, arguing that the current and coming environmental challenges are most effectively met if architects - as much as other designers - look to and learn from the natural world, finding relevant examples of biological and ecological systems that are then imitated. 'Human-made systems tend to use design to maximize for a single goal,' states the thoughtful Pawlyn, formerly part of the core team at Grimshaw, 'while ecosystems have evolved towards an optimized overall system.

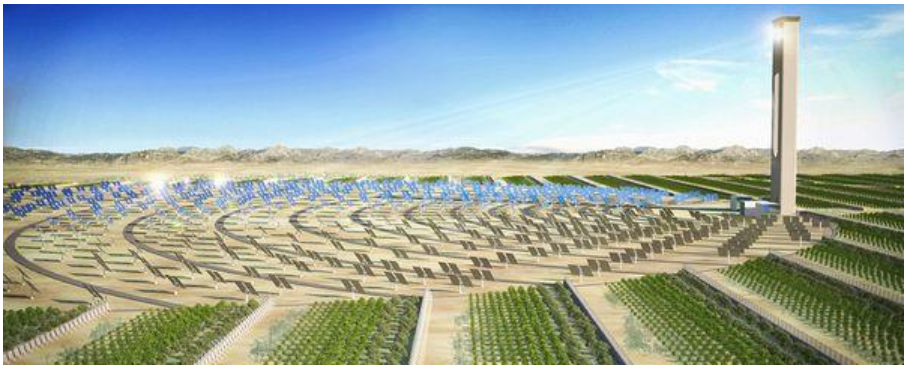

\section{REFERENCES}

[1]. Michael Pawlyn, (2011), Biomimicry in Architecture, Riba Publishing [2]. Janine M Benyus, (2002) Biomimicry: innovation inspired by nature, Harper Collins Publishers, New York.

[3]. Asknature.org

[4]. Eleven-magzine.com

[5]. www.ILBI.com

[6]. Biomimicry.net

[7]. Biomimicryindia.com

[8]. www.eol.org

[6]. Biomimicry.net

[7]. Petra Gruber, (2011) Biomimetics in Architecture: Architecture of Life and buildings, Springer Wien New York.

[8].

bhttp://www.biomimicryinstitute.org/about-us/what-is-biomimicry.html [9]. Dora Lee, (2011), Biomimicry invention inspired by nature, Kids Can press limited, Canada

[10]. Guild, B. (2007). Innovation inspired by nature work book.

Biomimicry Guild.

[11]. Ruchi Yadav, (May 2017) Architecture: Trends and design:

Architecture, Time, Space and People Magazine.

[12]. Asif. R. Khan, (May 2017) Concept design development: Architecture, Time, Space and People Magazine.

[13]. Vijesh Kumar, (April 2017) Voronoi and Sustainability: Architecture Time, Space and People Magazine.

[14]. Vedula VLN Murthy, (Jan 2012) Space and forms in architecture Architecture, Time, Space and People Magazine.

[15]. Shashank Chakradeo, (Dec 2013) Architecture: Inspiration from Nature: Architecture, Time, Space and People Magazine.

[16]. Modern Voice: Undistributed Nature (case study), (Feb 2014):

Architecture, Time, Space and People Magazine.

[17]. Rohit Raj, (Dec 2012) Exploring Identity: Symbolism in Architecture (Theory): Architecture, Time, Space and People Magazine.

[18]. Pranav Chahande, (Jan 2013) The New Morphogenesis (Shapes in

Architecture) (Concepts): Architecture, Time, Space and People Magazine

[19]. Alison, J., Brayer, M., \& Spiller, N. (2003). Future City:

Experiment and Utopia in Architecture. London: Thames \&

Hudson.

[20]. Benyus, J. M. (2014, 10 23). A Biomimicry Primer. Retrieved

from Biomimicry 3.8: Biomimicry.net.

[21]. Frosch, R. A., \& Gallapoulos, N. E. (1989). Strategies for

Manufacturing. Scientific American, 144-152.
[22]. Gruber, P. (2011). Biomimetics in Architecture, Architecture of Life and Buildings. Vienna: Springer-Verlag/Wien.

[23]. Jeronimidis, G., \& Gruber, P. (2012). Has Biomimetics Arrived in Architecture? Bioinspiration and Biomimetics, 1-2.

[24]. Mazzoleni, I., \& Price, S. (2013). Architecture Follows Nature, Biomimetic Principles for Innovative Design. Florida: CRC Press,

Taylor and Francis Group.

[25]. Myers, W. (2012). Beyond Biomimicry. In W. Myers, Bio Design (pp. 10-17). London: Thames \& Hudson.

[26]. $(2008,1210)$. Orquideorama_Equipment for the exhibition of orchids.

[27]. (2014, June 13). Flower Pots and Biomimicry: Natural Air Conditioning. Retrieved from Smart Living Network:

https://www.smartlivingnetwork.com/green/b/flower-pots-andbiomimicry-natural-air-conditioning/

[28]. transformKC. (n.d.). Grimshaw - Waterloo. Retrieved from TransFORM Kansas City:

http://transformkc.org/project/grimshaw-waterloo/

Zari, M. P. (2007). Biomimetic Approaches to Architectural Design for Increased Sustainability. Auckland, New Zealand.

Author: Shivi Pathak has recently completed Bachelor's degree program in Architecture from Hitkarini College of Architecture and Town Planning, Jabalpur (M.P.) affiliated to R.G.P.V. University, INDIA. 